\title{
Sexually Transmitted Infections Among Hospitalized Patients With Human Immunodeficiency Virus Infection and Acquired Immune Deficiency Syndrome (HIV/AIDS) in Zahedan, Southeastern Iran
}

\author{
Seyed Mohammad Hashemi-Shahri, ${ }^{1}$ Batool Sharifi-Mood, ${ }^{1}$ Hamid-Reza Kouhpayeh, ${ }^{1}$ Javad Moazen, \\ Mohsen Farrokhian, ${ }^{1}$ and Masoud Salehi1 ${ }^{1,}$ \\ ${ }^{1}$ Infectious Diseases and Tropical Medicine Research Center, Zahedan University of Medical Sciences, Zahedan, IR Iran \\ "Corresponding author: Masoud Salehi, Infectious Diseases and Tropical Medicine Research Center, Zahedan University of Medical Sciences, Zahedan, IR Iran. Tel: \\ +98-54132281012, Fax: +98-5413236722, E-mail: shahestan@gmail.com
}

Received 2015 February 21; Revised 2015 June 16; Accepted 2015 June 30.

\begin{abstract}
Background: Studies show that nearly 40 million people are living with human immunodeficiency virus infection and acquired immune deficiency syndrome (HIV/AIDS) around the world and since the beginning of the epidemic, about 35 million have died from AIDS. Heterosexual intercourse is the most common route for transmission of HIV infection (85\%). People with a sexually transmitted infection (STI), such as syphilis, genital herpes, chancroid, or bacterial vaginosis, are more likely to obtain HIV infection during sex. On the other hand, a patient with HIV can acquire other infections such as hepatitis C virus (HCV) and hepatitis B virus (HBV) and also STIs. Co-infections and co-morbidities can affect the treatment route of patients with HIV/AIDs. Sometimes, physicians should treat these infections before treating the HIV infection. Therefore, it is important to identify co-infection or comorbidity in patients with HIV|AIDS.

Objectives: This study was conducted in order to understand the prevalence of HIV/AIDS/STI co-infection.

Patients and Methods: In this cross-sectional study, we evaluated all HIV/AIDS patients who were admitted to the infectious wards of Boo-Ali hospital (Southeastern Iran) between March 2000 and January 2015. All HIV/AIDS patients were studied for sexually transmitted infections (STI) such as syphilis, gonorrhea, hepatitis B virus (HBV) and genital herpes. A questionnaire including data on age, sex, job, history of vaccination against HBV, hepatitis B surface antigen (HBsAg), hepatitis B core antibody (anti-HBc), hepatitis B surface antigen (anti-HBs), HCV-Ab, venereal disease research laboratory (VDRL) test, fluorescent treponemal antibody absorption (FTA-Abs) test, and urine culture was designed. Data was analyzed by the Chi square test and P values of $<0.05$ were considered significant.

Results: Among the 41 patients with HIV/AIDS (11 females and 30 males; with age range of 18 to 69 years) five cases (12.1\%) had a positive test (1:8 or more) for VDRL. The FTA-Abs was positive for all patients who were positive for VDRL. Gonorrhea was found in seven patients (17\%) and three cases had genital herpes in clinical examinations. All patients who had positive test results for these STIs were male. Eleven patients (26.8\%) had HBV infection (three females and eight males). hepatitis C virus (HCV) was found in 13 cases (31\%). Eighty percent of patients were unemployed. Seventy-eight percent of patients with HIV/STI were aged between 18 and 38 years. There was a significant difference between sex and becoming infected with HIV and also STI $(\mathrm{P}<0.05)$.

Conclusions: Patients with HIV/AIDS are more likely to acquire other STIs, because the same behaviors that increase the risk of becoming HIV infected can also increase the risk of acquiring STIs. Having a sore on the skin due to an STI can make the transmission of HIV to the sex partner more likely than people who don't have such sore in their genital area.
\end{abstract}

Keywords: AIDS, HBV, HIV, Syphilis, Co-infection

\section{Background}

Human immunodeficiency virus (HIV) is one of a group of viruses known as retroviruses. After acquiring the infection, this virus can damage or destroy immune cells especially T-cells in the body and progressively decreases the immune system to fight against infections ( 1 ,
2). The HIV infection can lead to acquired immunodeficiency syndrome (AIDS) when the virus has destroyed the body's defenses and immune-T-cell counts fall to critical levels. At this time, the person becomes susceptible to lifethreatening infections. These infections, which occur with AIDS, are called opportunistic infections (OI) $(1,3)$. Most commonly, HIV infection is transmitted through sex with 
an infected partner. The virus can also transmit through the lining of the vagina, penis, and the mouth during sexual activity. Human immunodeficiency virus commonly spreads among injection-drug users (IDUs) who share their needles or syringes, which are contaminated with infected blood. Mothers can transmit HIV to their children during pregnancy or at birth (4-6). Among transmission routes, sexual intercourse is the most common way and during sex other STIs can be transmitted to the other partner when the index case is infected by such STIs. Also, individuals who have a sexually transmitted infection, such as syphilis, human Papillomavirus (HPV), genital herpes, chlamydia, gonorrhea, or bacterial vaginosis, are more likely (sometime 10-fold) to acquire HIV infection during sex with an infected partner (3-15). In contrast, genital ulcer diseases such as syphilis, chancroid and genital herpes are primarily transmitted through contact with infected mucosal surfaces or infected skin $(3,8,9)$. The most important preventative route is using latex condoms. When condoms are used correctly and consistently, they can minimize the risk of transmission of HIV and other STIs $(2,8)$. People with $\mathrm{HIV}$ infection can acquire other infections such as $\mathrm{HCV}, \mathrm{HBV}$ and STI, because the transmission routes are similar. Coinfections can affect the treatment route of patients with HIV/AIDs. Sometimes, physicians should treat these infections (HCV) and then move on to treating the HIV infection. Therefore, it is important to identify co-infection or comorbidity in patients with HIV/AIDS. There are many reports, which explain the impact of HIV on STIs, and STIs on HIV infection (3-22). Here, we aimed to investigate the prevalence of co-infection of HIV/AIDS and STIs.

\section{Objectives}

The aim of this study was to investigate the prevalence of HIV/AIDS and STI co-infection amongst a group of patients from the city of Zahedan.

\section{Patients and Methods}

In this cross-sectional study, we evaluated all HIV/AIDS patients who were admitted to the infectious wards of BooAli hospital Zahedan, Southeastern Iran) between March 2000 and January 2015. These patients had been hospitalized to infectious wards for different infectious diseases including pulmonary and urinary tract infections, skin infections, tuberculosis, sepsis and fungal diseases. According to the guide lines at our infectious ward, all HIV/AIDS patients were also tested for sexually transmitted infections such as syphilis, gonorrhea, genital herpes, and hepatitis $\mathrm{B}$ and $\mathrm{C}$ virus. A questionnaire including data on age, sex, job, hepatitis B surface Antigen (HBsAg), hepatitis B core antibody (anti-HBc), hepatitis B surface antigen (antiHBs), HCV-Ab, history of vaccination against HBV, Venereal Disease Research Laboratory (VDRL) test, Fluorescent Treponemal Antibody Absorption test (FTA-Abs) and urine culture was designed. Enzyme-Linked Immunosorbent Assay (ELISA) was done for determining the presence of HBV and HCV infections. Gonorrhea was detected by urine smear and/or culture. Unfortunately, only 11 among 41 patients with HIV|AIDS were treated by antiretroviral agents, and others were not tested for cluster of differentiation 4 (CD4) and viral load. Their files showed only a positive ELISA test for HIV and they were referred to the HIV center, and we could not follow them as they were from different parts of Sistan and Baluchestan province. Results were analyzed using the SPSS software (version 18). Chi square and Fisher exact tests were used to compare the seroprevalence and characteristics of the patients. P values of $<0.05$ were considered significant.

\section{Results}

We evaluated 41 patients with HIV/AIDS (11 females and 30 males; with an age range between 18 and 69 years) who were hospitalized during 15 years at Boo-Ali hospital (Southeastern Iran). Among this group, five cases (12.1\%) had a positive test (1:8 or more) for VDRL. The FTA-ABS test was positive for all patients who had positive VDRL test results. Gonorrhea was found in seven patients (17\%) and three cases had genital herpes indicated by clinical examinations. All patients who were positive for STI (except HBV) were from male. Eleven patients (26/8\%) were positive for hepatitis B virus (three females and eight males) (Table 1). All cases with HBV infection were healthy carriers and had no history of vaccination against HBV and HAV. hepatitis $C$ virus (HCV) was found in 13 cases (31\%). There was a significant difference between sex and acquiring HIV and also STI $(\mathrm{P}<0.05)$. Eighty percent of patients were unemployed when they had been referred to the hospital. The difference between STI and the age of patients was significant. Seventy-eight percent of patients with HIV/STI were aged between 18 and 38 years (Table 2). Co-infection with HIV/syphilis/HBV was found in three patients.

\section{Discussion}

Our study showed that males are more susceptible than females for acquiring HIV and STI. On the other hand, one of the most important factors for acquiring HIV and STI was being jobless. Unemployment can lead to addiction and injecting drug use (IDU) and this can increase the 
Table 1. Prevalence of Sexually Transmitted Infections in Patients with Human Immunodeficiency Virus According to Sex

\begin{tabular}{lcccc}
\hline Sex & & & STI & \\
\cline { 2 - 5 } & Syphilis & Gonorrhea & Genital Herpes & HCV \\
\hline Male & 5 & 7 & 3 & 0 \\
\hline Female & 0 & 0 & 3 & 3 \\
\hline
\end{tabular}

Table 2. Prevalence of Sexually Transmitted Infection in Patients With Human Immunodeficiency Virus According to Age

\begin{tabular}{lcccc}
\hline Sex & \multicolumn{2}{c}{ Age, y } \\
\cline { 2 - 4 } & $\mathbf{1 8 - 2 7}$ & $\mathbf{2 8 - 3 7}$ & $\mathbf{3 8 - 4 7}$ & $\mathbf{4 7}$ \\
\hline Male & 9 & 6 & 2 & 0 \\
Female & 2 & 1 & 0 \\
\hline
\end{tabular}

chance of acquiring all STIs including HIV infection. The presence of an ulcerative STI increases the risk of becoming infected with HIV. These findings were also reported in many previous studies (2-5). Also, when a person has HIV, they can become infected with other STIs due to unsuitable and high-risk behaviors. In our study like many previous reports, prevalence of HIV and STI was more in males than in females and unemployment had a significant role in this regard. The association between HIV and STI has also been reported by Chen et al. and Sexton et al. $(3,4)$. Zetola et al. studied 36 males with acute HIV infection who had sex with males (MSM). They found that having an STI in the previous three months increased the chance of HIV acquisition compared to those who had STIs in the last 12 months (5). Chen and Zetola studies showed that HIV and STI coinfection was higher in males than females. This finding was also seen in our research. Tobian reported that infection with herpes simplex virus (HSV)-2 increased HIV incidence by three folds, while incidence of HSV-1 increased by six folds (7). Glynn et al. also reported that infection with HSV-2 increased the rate of infection with HIV. After adjusting for age and sexual behavior the relative risk for prevalence of HSV-2 and incidence of HIV was 1.5 for sex workers and 1.6 for MSM (6). The study of Johnson and Lewis showed that the presence of polymorphonuclear leukocytes in the genital tract was associated with an increase in the shedding of HIV similar to what is seen with chlamydia and gonorrhea. Also, they found the odds of detection of HIV in the genital tract in the presence of protean microorganisms (17). They reported significant associations between HIV infection and urethritis (OR 3.1, 95\% CI: 1.1 8.6), chlamydia (OR 1.8, 95\% CI: 1.1 - 3.1), vulvovaginal candidiasis (OR1.8, 95\% CI:1.3 - 2.4) and gonorrhoea (OR1.8, 95\% CI: 1.2 - 2.7). A study by Marschalko et al. reported that coinfection (such as HIV and hepatitis B virus, HIV and hep- atitis $\mathrm{C}$ virus, HIV and syphilis, HIV and gonorrhoea, HIV and chlamydia coinfections) was more frequent in HIV infected patients than in the normal population (19). Chow et al. conducted a systematic review and meta-analysis of the literature published between years 2004 and 2011. They found that the prevalence of HIV, syphilis, and co-infection with HIV/Syphilis among 'money boys' ('money boys' are a group of men who commercially sell sex to other men) was $6.0 \%, 12.4 \%$ and $2.2 \%$, respectively (21). Another study in 2015 reported that the prevalence of HIV was very high among money boys and $61.2 \%$ of this group had STIs (23). Sexually transmitted infections (Stis) are some of the most preventable infections in the world. Nearly half of all STIs occur in people younger than 25 years old when sexual activity is high. Transmission of STI to others is more likely if the person has more than one sex partner or does not use condoms or fails to use it correctly $(1,2,8)$. Many people may not show any signs and symptoms of STIs, yet they are able to spread infection to their partners. There are at least 20 different STIs. Some of the most common STIs include chlamydia, genital herpes, gonorrhea, hepatitis B, syphilis, trichomoniasis, hepatitis $\mathrm{C}$ virus (HCV) and human immunodeficiency virus (HIV), which causes AIDS (36). Having other STIs, such as genital herpes, can increase the risk of HIV. The presence of an untreated STI (ulcerative; such as genital herpes and non-ulcerative like gonorrhea) increases the risk of becoming infected with HIV (15-18). All presented reports indicated that having an STI can increase the risk of acquiring HIV infection and someone who has HIV can acquire other STIs. These results were also found in our study. Early diagnosis and treatment of all STIs is important and more important is the prevention of infection by suitable routes, with the use of condoms being the best $(2,8,24)$. All individuals with HIV infection should be vaccinated against hepatitis A and B, pneumococcal infection, 
influenza and varicella. Females with HIV infection should also be screened annually for trichomoniasis, and all infected cases should undergo annual screening for syphilis, gonorrhea and chlamydia $(2,8,13,18)$.

\subsection{Conclusion}

Having an STI can increase the risk of becoming infected with HIV. Using condoms correctly and limiting sexual partners and avoiding injecting drug use are major factors for prevention of STI and HIV. Having a job is another important factor to minimize the risk of acquiring HIV and STI.

\section{Acknowledgments}

We would like to thank Mrs Soroush, Mrs Jokar, Mrs Mokhtati, Mrs Behzadmanesh, Mrs Akbari, and Mrs Asghari, who helped us in this research.

\section{Footnote}

Authors' Contribution: Seyed Mohammad HashemiShahri, Batool Sharifi-Mood and Hamid-reza Kouhpayeh designed the study. Javad Moazen and Mohsen Farrokhian collected the data. Masoud Salehi corrected the paper. All authors had an equal role in the writing of the manuscript.

\section{References}

1. Weber JN, McCreaner A, Berrie E, Wadsworth J, Jeffries DJ, Pinching AJ, et al. Factors affecting seropositivity to human T cell lymphotropic virus type III (HTLV-III) or lymphadenopathy associated virus (LAV) and progression of disease in sexual partners of patients with AIDS. Genitourin Med. 1986;62(3):177-80. [PubMed: 3015772].

2. Adimora AA, Schoenbach VJ, Floris-Moore MA. Ending the epidemic of heterosexual HIV transmission among African Americans. Am J Prev Med. 2009;37(5):468-71. doi:10.1016/j.amepre.2009.06.020. [PubMed: 19840704].

3. Chen YC, Liu HY, Li CY, Lee NY, Li CW, Ko WC, et al. The rising trend of sexually transmitted infections among HIV-infected persons: a population-based cohort study in Taiwan, 2000 through 2010. J Acquir Immune Defic Syndr. 2015;68(4):432-8. doi: 10.1097/QAI.0000000000000477. [PubMed: 25501610].

4. Sexton J, Garnett G, Rottingen JA. Metaanalysis and metaregression in interpreting study variability in the impact of sexually transmitted diseases on susceptibility to HIV infection. Sex Transm Dis. 2005;32(6):351-7. [PubMed: 15912081].

5. Zetola NM, Bernstein KT, Wong E, Louie B, Klausner JD. Exploring the relationship between sexually transmitted diseases and HIV acquisition by using different study designs. J Acquir Immune Defic Syndr. 2009;50(5):546-51. [PubMed: 19367993]

6. Glynn JR, Biraro S, Weiss HA. Herpes simplex virus type 2: a key role in HIV incidence. AIDS. 2009;23(12):1595-8. doi: 10.1097/QAD.0b013e32832e15e8. [PubMed: 19512858].

7. Tobian AA, Ssempijja V, Kigozi G, Oliver AE, Serwadda D, Makumbi $F$, et al. Incident HIV and herpes simplex virus type 2 infection among men in Rakai, Uganda. AIDS. 2009;23(12):1589-94. doi: 10.1097/QAD.0b013e32832d4042. [PubMed: 19474649]
8. Kamali A, Quigley M, Nakiyingi J, Kinsman J, Kengeya-Kayondo J, Gopal $\mathrm{R}$, et al. Syndromic management of sexually-transmitted infections and behaviour change interventions on transmission of HIV-1 in rural Uganda: a community randomised trial. Lancet. 2003;361(9358):64552. [PubMed: 12606175$]$.

9. Van de Wijgert JH, Morrison CS, Brown J, Kwok C, Van Der Pol $\mathrm{B}$, Chipato $\mathrm{T}$, et al. Disentangling contributions of reproductive tract infections to HIV acquisition in African Women. Sex Transm Dis. 2009;36(6):357-64. doi: 10.1097/OLQ.0b013e3181a4f695. [PubMed 19434010].

10. Bernstein KT, Marcus JL, Nieri G, Philip SS, Klausner JD. Rectal gonorrhea and chlamydia reinfection is associated with increased risk of HIV seroconversion. J Acquir Immune Defic Syndr. 2010;53(4):537-43. doi:10.1097/QAI.0b013e3181c3ef29. [PubMed: 19935075].

11. Jin F, Prestage GP, Imrie J, Kippax SC, Donovan B, Templeton DJ, et al. Anal sexually transmitted infections and risk of HIV infection in homosexual men. J Acquir Immune Defic Syndr. 2010;53(1):144-9. doi: 10.1097/QAI.0b013e3181b48f33. [PubMed: 19734801].

12. Chin-Hong PV, Husnik M, Cranston RD, Colfax G, Buchbinder S Da Costa M, et al. Anal human papillomavirus infection is associated with HIV acquisition in men who have sex with men. AIDS. 2009;23(9):1135-42. doi: 10.1097/QAD.0b013e32832b4449. [PubMed 19390418].

13. Sasse A, Defraye A. HIV infections and STI co-infections in men who have sex with men in Belgium: sustained increase in HIV diagnoses. Euro Surveill. 2009;14(47) [PubMed: 19941801].

14. Miller M, Liao Y, Wagner M, Korves C. HIV, the clustering of sexually transmitted infections, and sex risk among African American women who use drugs. Sex Transm Dis. 2008;35(7):696-702. doi: 10.1097/OLQ.0b013e31816b1fb8. [PubMed: 18418289].

15. Patterson TL, Goldenberg S, Gallardo M, Lozada R, Semple SJ, Orozovich $\mathrm{P}$, et al. Correlates of HIV, sexually transmitted infections, and associated high-risk behaviors among male clients of female sex workers in Tijuana, Mexico. AIDS. 2009;23(13):1765-71. doi: 10.1097/QAD.0b013e32832fo8a1. [PubMed: 19584699].

16. McCoy SI, Eron JJ, Kuruc JD, Strauss RP, Macdonald PD, Fiscus SA et al. Sexually transmitted infections among patients with acute HIV in North Carolina. Sex Transm Dis. 2009;36(6):372-4. doi: 10.1097/OLQ.0b013e3181997252. [PubMed: 19387421].

17. Johnson LF, Lewis DA. The effect of genital tract infections on HIV-1 shedding in the genital tract: a systematic review and meta-analysis. SexTransm Dis. 2008;35(11):946-59. doi:10.1097/OLQ.ob013e3181812d15. [PubMed: 18685546].

18. Brown MJ, Pugsley R, Cohen SA. Meeting sex partners through the Internet, risky sexual behavior, and HIV testing among sexually transmitted infections clinic patients. Arch Sex Behav. 2015;44(2):509-19. doi: 10.1007/s10508-014-0463-3. [PubMed: 25567074].

19. Marschalko M, Ponyai K, Karpati S. Sexually transmitted coinfections. HIV coinfections [in Hungarian]. Orv Hetil. 2015;156(1):4-9. doi: 10.1556/OH.2015.30076. [PubMed: 25544048].

20. Munoz-Laboy M, Severson N, Bannan S. Occupations, social vulnerability and HIV/STI risk: The case of bisexual Latino men in the New York City metropolitan area. Glob Public Health. 2014;9(10):1167-83. doi: 10.1080/17441692.2014.961948. [PubMed: 25299059].

21. Chow EP, Iu KI, Fu X, Wilson DP, Zhang L. HIV and sexually transmissible infections among money boys in China: a data synthesis and meta-analysis. PLoS One. 2012;7(11):48025. doi: 10.1371/journal.pone.0048025. [PubMed: 23209551].

22. Fogel CI, Gelaude DJ, Carry M, Herbst JH, Parker S, Scheyette A, et al. Context of risk for HIV and sexually transmitted infections among incarcerated women in the south: individual, interpersonal, and societal factors. Women Health. 2014;54(8):694-711. doi: 10.1080/03630242.2014.932888. [PubMed: 25204565]. 
23. Figueroa JP, Cooper CJ, Edwards JK, Byfield L, Eastman S, Hobbs MM, et al. Understanding the high prevalence of HIV and other sexually transmitted infections among socio-economically vulnerable men who have sex with men in Jamaica. PLoS One. 2015;10(2):0117686. doi: 10.1371/journal.pone.0117686. [PubMed: 25659122].
24. Kayembe PK, Mapatano MA, Busangu AF, Nyandwe JK, Musema GM, Kibungu JP, et al. Determinants of consistent condom use among female commercial sex workers in the Democratic Republic of Congo: implications for interventions. Sex Transm Infect. 2008;84(3):202-6. doi: 10.1136/sti.2007.028324. [PubMed: 18055581]. 